\title{
Diabetes in pregnancy: A comparison of guidelines
}

\author{
Muneera Ahmed AlKhalifa ${ }^{1}$, Stephanie $\mathrm{Hsu}^{2}$, Gulmeen $\operatorname{Raza}^{3}$ and M. Samy Ismail ${ }^{3 *}$ \\ ${ }^{1}$ King Hamad University Hospital, Al Sayh, Kingdom of Bahrain \\ ${ }^{2}$ Research Department, King Hamad University Hospital, Al Sayh, Kingdom of Bahrain \\ ${ }^{3}$ Department of Obstetrics and Gynecology, King Hamad University Hospital, Al Sayh, Kingdom of Bahrain
}

\begin{abstract}
Introduction: Diabetes in pregnancy is becoming increasingly prevalent worldwide and managing such patients remains challenging. The aim of this comparison is to help reach a consensus regarding the most reasonable approach to care for such patients and modify our institute's guidelines where necessary.

Methods: This is a review article comparing the most recent guidelines available concerning the diagnosis and management of diabetes in pregnancy, which includes both pre-gestational and gestational. The following guidelines will be compared; the National Institute for Health and Care Excellence (NICE), World Health Organization (WHO), American College of Obstetricians and Gynecologists (ACOG), American Diabetes Association (ADA), the Society of Obstetricians And Gynecologists Of Canada (SOGC), Canadian Diabetes Association (CDA), and the International Federation of Gynaecology and Obstetrics (FIGO). These recommendations will also be compared to the current guidelines set in our institute, King Hamad University Hospital (KHUH) in the Kingdom of Bahrain.
\end{abstract}

Results: The similarities and differences between the guidelines will be highlighted in the form of tables and a brief discussion. The tables will emphasize the differences in screening, diagnosing, and managing diabetes in pregnancy.

Conclusion: Updating our guidelines to remain consistent with international guidelines can help unify our institute's approach to managing such patients thus ensuring the provision of the highest quality of care.

\begin{abstract}
Abbreviations: ACOG: American College of Obstetrics and Gynecology; ACEI: Angiotensin Converting Enzyme Inhibitor; ADA: American Diabetes Association; ARB: Angiotensin II Receptor Blocker; BMI: Body Mass Index; CDA: Canadian Diabetes Association; DIP: Diabetes in Pregnancy; DM: Diabetes Mellitus; DR: Diabetic Retinopathy; EFW: Estimated Fetal Weight; eGFR: Estimated Glomerular Filtration Rate; ELCS: Elective Cesarean Section; FIGO: International Federation of Gynaecology and Obstetrics; FPG: Fasting Plasma Glucose; GCT: Glucose Challenge Test; GDM: Gestational Diabetes Mellitus; HbA1c: Glycosylated hemoglobin (hemoglobin A1c) IADPSG: International Association of Diabetes and Pregnancy Study Groups; IGT: Impaired Glucose Tolerance; IOL: Induction of Labor; IUD: Intrauterine Contraceptive Device; KHUH: King Hamad University Hospital; LGA: Large for Gestation Age; MNT: Medical Nutrition Therapy; NICE: National Institute for Health and Care Excellence; NICU: Neonatal Intensive Care Unit; OCP: Oral Contraceptive Pill; OGTT: Oral Glucose Tolerance Test; OHA: Oral Hypoglycemic Agents; PED: Pre-existing Diabetes; PET: Pre-eclamptic Toxemia; PG: Plasma Glucose; POP: Progesterone-only Pill; RCOG: Royal College of Obstetricians and Gynaecologists; RPG: Random Plasma Glucose; SGA: Small for Gestation Age; SMBG: Self-monitoring of Blood Glucose; SOGC: Society of Obstetricians and Gynaecologists of Canada; UAC: Urine Albumin to Creatinine; T1DM: Type 1 Diabetes Mellitus; T2DM: Type 2 Diabetes Mellitus; TSH: Thyroid Stimulating Hormone; WHO: World Health Organization.
\end{abstract}

\section{Introduction}

Gestational diabetes mellitus (GDM) is an asymptomatic condition that warrants screening and treating [1]. GDM is defined as "carbohydrate intolerance resulting in hyperglycemia of variable severity with onset or first recognition during pregnancy" $[2,3]$. GDM is becoming more prevalent as global obesity rates increase $[4,5]$. The prevalence of GDM worldwide reaches up to $28 \%$ [6]. One-sixth of live births are born to a mother with hyperglycemia: $84-90 \%$ have GDM while $10-16 \%$ have pre-existing diabetes (PED) [5-7]. Unlike GDM, which mostly occurs after 24 weeks, PED can be diagnosed at any time during pregnancy [6]. The prevalence of both type 1 diabetes mellitus (T1DM) and type 2 diabetes mellitus (T2DM) is increasing worldwide [5]. In addition, the age of onset of T2DM is decreasing and is starting to include women with childbearing potential [6]. T1DM is an autoimmune process characterized by the destruction of $\beta$ pancreatic cells, while T2DM is characterized by relative insulin deficiency resulting from peripheral resistance [7].

Factors that increase the risk of developing GDM include obesity, older age, higher parity, excessive weight gain during pregnancy, family history of diabetes and previous GDM [6]. Hyperglycemia in pregnancy, whether due to PED or GDM, is associated with both maternal and fetal complications [3]. Maternal complications include

${ }^{\star}$ Correspondence to: Mahmoud Samy Ismail (MBBCH, MA, MD, Facharzt, MD, PhD), Department of Obstetrics and Gynecology, King Hamad University Hospital, Building 2345, Road 2835, Block 228, P. O. Box 24343, Busaiteen, Kingdom of Bahrain, Tel: (973) 35593048, E-mail: samyismael@hotmail.com

Key words: gestational diabetes mellitus (GDM), diabetes in pregnancy, pregestational diabetes mellitus, oral glucose tolerance test (OGTT), guidelines for management of GDM

Received: December 29, 2020; Accepted: January 18, 2021; Published: January 22,2021 
developing PET, preterm labor, thromboembolism, postpartum hemorrhage and subsequent T2DM [4-7]. Around 50\% of women who had GDM developed T2DM within 5 years after birth and up to $70 \%$ developed it within $15-25$ years $[2,4,5]$. Fetal complications of GDM include macrosomia, increased incidence of birth trauma, respiratory distress syndrome, hypoglycemia, polycythemia and hyperbilirubinemia [2,4-7]. Furthermore, hyperglycemia, particularly at the time of organogenesis (early in the first trimester), is associated with spontaneous abortions and congenital anomalies [6].

Treating diabetes in pregnancy aims to achieve several outcomes, one of which is optimizing fetal growth. Other reasons include reducing the risk of fetal death, pre-eclamptic toxemia (PET), Cesarean section and birth trauma [1]. Treating GDM has been found to be associated with reducing the incidence of macrosomia, shoulder dystocia, large for gestational age (LGA) and PET [3]. Poorly controlled PED is associated with grave end-organ damage, particularly microangiopathy [7]. Patients with PED might already have co-morbidities, which further increases the risks of complication associated with conception for both the mother and her fetus [4-6]. Additionally, the duration of the disease is directly related to the propensity for complications [5].

The incidence of GDM in Bahrain has increased from 5.4\% in 1989 to $7.2 \%$ in 2002 to $12.5 \%$ in 2010 . The rate of advanced maternal age and obesity are also increasing within the country, both of which are known to increase the risk of GDM [8]. This could imply that the rate of GDM has been on a constant rise.

A variation of practices was found among international guidelines regarding diabetes in pregnancy. The biggest differences were found in diagnostic criteria, timing of delivery and postnatal care. This review article aims at comparing seven of the most recent international guidelines along with the current guidelines in our institute (King Hamad University Hospital (KHUH)) on the diagnosis and treatment of women with PED and GDM.

\section{Discussion}

\section{Diabetes in pregnancy: A comparison of current guidelines}

Preconception counseling for PED: Preconception care is highly essential, especially for diabetic patients. It is estimated that only about $30-50 \%$ of pregnancies are planned and received proper care [6]. Patients who are planning to get pregnant should seek prenatal care to get educated on the risks associated with pregnancy and the necessary precautions to take [4-7]. A multidisciplinary approach to patients is highly crucial. Healthcare professionals involved include an obstetrician, perinatologist, diabetic educator, endocrinologist, nurse and midwife among others [4,9]. Glycemic control prior to conception is critical since babies born to diabetic mothers are more susceptible to congenital malformations, miscarriage, stillbirth and neonatal death in the event of poor blood glucose control [4,5,7]. An HbAlc of less than $6.5 \%$ has been found to reduce this risk $[4,5,9]$. NICE advises against pregnancy if $\mathrm{HbAlc}$ is greater than $10 \%$ [5]. Patients are advised to stop taking teratogenic medications such as ACEIs, ARBs and statins $[1,4,5,7,9]$. These medications are associated with fetal renal dysplasia, oligohydramnios and intrauterine growth restriction (IUGR) [4,9]. Also, chronic diuretic use in pregnancy restricts maternal plasma volume hence leading to decreased uteroplacental perfusion [4]. They are also advised to start taking folic acid until 12 weeks of gestation $[1,4,5,7,9]$ (Table 1$)$. Folic acid can help reduce the risk of neural tube defects [5].

Women with PED might have undiagnosed diabetic complications such as retinopathy and nephropathy [6]. Retinal assessment should be done at booking or before conception $[1,4,5,7,9]$. As per CDA, it might be necessary to repeat throughout pregnancy in cases of severe diabetic retinopathy (DR) [9] (Table 1). Retinal assessment should continue even postpartum, starting with 1 year postpartum and annually if no signs of DR $[1,5,7,9]$. Women with PED should be warned against rapid optimization of glucose control prior to completing their retinal assessment [5]. One-third of DR cases progress due to strict glycemic

Table 1. Preconception care for ped

\begin{tabular}{|c|c|c|c|c|}
\hline & KHUH & NICE & SOGC/CDA & ACOG/ADA \\
\hline Contraception & NA & $\begin{array}{l}\text { Choice depends on patient's preference } \\
\text { and risk factors }\end{array}$ & $\begin{array}{l}\text { Risk factors/contraindications } \\
\text { estrogen: progestin-only or IUD }\end{array}$ & $\begin{array}{l}\text { OCP if no vasculopathy Otherwise, } \\
\text { POP, IUD or implantable progestin. }\end{array}$ \\
\hline Counseling & $\begin{array}{l}\text { Risks of pregnancy } \\
\text { Optimization of glucose control } \\
\text { Team: obstetrician, dietitian, } \\
\text { endocrinologist, diabetic educator }\end{array}$ & $\begin{array}{l}\text { Risks of pregnancy } \\
\text { Optimization of glucose control } \\
\text { Hypoglycemia and awareness } \\
\text { Diet and exercise } \\
\text { Weight loss advice if } \mathrm{BMI}>27 \mathrm{~kg} / \mathrm{m}^{2}\end{array}$ & $\begin{array}{l}\text { Optimization of glucose control } \\
\text { Nutrition } \\
\text { Team: obstetrician, dietitian, } \\
\text { endocrinologist, diabetic educator }\end{array}$ & $\begin{array}{l}\text { Risks of pregnancy } \\
\text { Smoking cessation } \\
\text { Team: maternal-fetal medicine } \\
\text { specialist, endocrinologist, dietitian, } \\
\text { diabetic educator }\end{array}$ \\
\hline Folic Acid Supplementation & $\begin{array}{c}5 \mathrm{mg} 12 \text { weeks preconception until } \\
12 \text { weeks gestation }\end{array}$ & $5 \mathrm{mg}$ until 12 weeks gestation & $\begin{array}{l}1 \mathrm{mg} \text { (higher dose for obese) } \\
12 \text { weeks preconception until } \\
12 \text { weeks gestation }\end{array}$ & $\begin{array}{c}0.4 \mathrm{mg} \\
(0.8-1 \mathrm{mg} \text { if high risk })\end{array}$ \\
\hline Teratogenic Medications & Stop ACEIs and statins & \multicolumn{3}{|c|}{ Stop ACEIs, ARBs, statins } \\
\hline Retinal Assessment & \multicolumn{2}{|c|}{$\begin{array}{l}\text { Perform at booking if not done within past } 6 \text { months } \\
\text { Signs of DR at booking: repeat at } 16-20 \text { weeks } \\
\text { No signs of DR at booking: repeat at } 28 \text { weeks }\end{array}$} & $\begin{array}{l}\text { Before conception } \\
\text { Every trimester } \\
1 \text { year postpartum }\end{array}$ & \\
\hline Renal Assessment & $\begin{array}{l}\text { Baseline renal function if not done } \\
\text { within past year }\end{array}$ & $\begin{array}{l}\text { Screen for albuminuria } \\
\text { Refer to nephrology if: } \\
\text { Serum creatinine } \geq 120 \mu \mathrm{mol} / \mathrm{L} \\
\text { Or UAC ratio }>30 \mathrm{~g} / \mathrm{mmol} \\
\text { Or eGFR }<45 \mathrm{ml} / \mathrm{min} / 1.73 \mathrm{~m}^{2}\end{array}$ & $\begin{array}{l}\text { Serum creatinine, proteinuria } \\
\text { Screen for albuminuria and chronic } \\
\text { kidney disease }\end{array}$ & $\begin{array}{l}\text { 24-hour urine collection for } \\
\text { proteinuria and creatinine clearance if } \\
\text { not done within past year. } \\
\text { Measure serum creatinine and UAC } \\
\text { ratio }\end{array}$ \\
\hline Others & TSH and ECG & \multicolumn{2}{|c|}{ NA } & $\begin{array}{l}\text { Lipid assessment } \\
\text { TSH and ECG }\end{array}$ \\
\hline
\end{tabular}

Abbreviations: NA: not applicable; PED: pre-existing diabetes; IUD: intrauterine contraceptive device; OCP: oral contraceptive pill; POP: progesterone-only pill; BMI: body mass index; ACEI: angiotensin converting enzyme inhibitor; ARB: angiotensin II receptor blocker; DR: diabetic retinopathy; UAC: urine albumin to creatinine; eGFR: estimated glomerular filtration rate; TSH: thyroid stimulating hormone; ECG: electrocardiogram 
control early in pregnancy [7]. Panretinal photocoagulation can be performed prior to pregnancy in those with proliferative DR [7,9].

5-10\% of pregnant, diabetic women have diabetic nephropathy [7]. Renal function should also be performed and referral to nephrology might be deemed necessary. Several screening tests include checking for albuminuria, proteinuria, eGFR, creatinine and UAC ratio $[4,5,7,9]$ a UAC ratio greater than $30 \mathrm{mg} / \mathrm{mmol}$ is the threshold for defining severe chronic kidney disease [5] (Table 1). Albuminuria and overt nephropathy are associated with an increased risk for both maternal and fetal complications [9]. Increased urinary protein excretion in early pregnancy increases the risk for hypertension [9]. Both NICE and the Canadian guidelines agree that eGFR should not be used during pregnancy because it can underestimate glomerular filtration rate; instead serum creatinine should be used [5,9]. Serum creatinine of more than $1.5 \mathrm{mg} / \mathrm{dL}$ is associated with an increased risk of progression to end-stage renal disease [7].

Hypertension is present in 5-45\% of pregnant women with PED $[7,9]$. The CDA noted that PET is more associated with T1DM while chronic hypertension is more associated with T2DM [9]. Hypertension, especially when combined with nephropathy increases the risk of PET, uteroplacental insufficiency and subsequent stillbirth [7]. ACOG advises a baseline ECG prior to conception to assess for pre-existing coronary artery disease since cardiovascular hemodynamics vary in pregnancy thus increasing the risk for myocardial infarction [7]. Thyroid function tests can help detect any pre-existing thyroid dysfunction, which is found in $40 \%$ of women with T1DM [7].

GDM screening: Insulin resistance increases in pregnancy and is well established at 24 weeks [6]. All guidelines recommend screening for GDM between 24-28 weeks [1-6,9]. There is no evidence that diagnosing or treating GDM before $24-28$ weeks is beneficial. Also, testing early in the first trimester can lead to over-diagnosing GDM especially when using a cutoff point of FPG $\geq 5.1 \mathrm{mmol} / \mathrm{L}$ [3]. Besides, diagnosing GDM is associated with increased monitoring and interventions [5]. Interestingly, SOGC claims that $22-27 \%$ of women are diagnosed with GDM before 24 weeks [1].

NICE and ACOG advise OGTT at booking if patients previously had GDM or other risk factors mentioned below [2,5]. FIGO recommends screening of all patients with fasting plasma glucose (FPG), random plasma glucose (RPG) or HbAlc at booking [6]. CDA noted that patients with risk factors should be screened with HbAlc, except those with hemoglobinopathy or renal disease who should be screened with FPG, because in their case, HbAlc is not reliable [9]. Screening for DM at booking with $\mathrm{HbA1c}$ can detect PED [5]. Even if screening was done early in pregnancy, whether with an OGTT or others, it is still to be repeated at 24-28 weeks.

Both NICE and WHO advocate what is known as selective testing, meaning, only those with risk factors should undergo screening at 2428 weeks $[3,5,6]$ (Table 2). Such risk factors include a BMI of more than $30 \mathrm{~kg} / \mathrm{m}^{2}$, previous GDM, previous macrosomia, family history of diabetes and ethnicity with high prevalence of DM [3,5]. Also, both NICE and WHO recommend screening for undiagnosed GDM in case of glycosuria showing $2+\leq$ once or $1+\leq$ twice or more $[3,5]$.

Diagnostic criteria for diabetes: The American and Canadian guidelines proposed two methods for screening for GDM. The first method consists of one step which is the $75 \mathrm{~g} 2$-hr OGTT. They both have the same diagnostic values $[1,2,4,9]$ (Table 3 ). NICE has a higher diagnostic FPG value of $5.6 \mathrm{mmol} / \mathrm{L}$ or more but a lower diagnostic value 2-hours post-prandially of $7.8 \mathrm{mmol} / \mathrm{L}$ or less. However, both the American and Canadian guidelines have variations of a two-step method. Initially, they both start with a $50 \mathrm{~g}$ GCT and if 1-hour postprandially, $\mathrm{PG}$ is $7.8 \mathrm{mmol} / \mathrm{L}$ or more, then the patient proceeds to the next step $[1,2,4,9]$. The $50 \mathrm{~g}$ GCT cannot independently diagnose diabetes because it cannot detect those with isolated high FPG and only has a sensitivity of $76.6 \%$ [1]. According to SOGC and CDA, blood glucose of $11 \mathrm{mmol} / \mathrm{L}$ or more is diagnostic of GDM, hence, there is no need to proceed with next step, which is $75 \mathrm{~g}$ 2-hr OGTT [1,9]. However, ACOG and ADA recommend $100 \mathrm{~g}$ 3-hr OGTT as the next step $[2,4]$. WHO divided the criteria for diagnosing hyperglycemia in pregnancy, using the $75 \mathrm{~g} 2$-hr OGTT, into two categories: diabetes in pregnancy and gestational diabetes mellitus. And FIGO followed suit $[3,6]$ (Table 2).

Glucose monitoring: Both American and Canadian guidelines recommend monitoring blood glucose levels 4-7 times daily in patients with PED: fasting, before and after meals [1,4,7,9]. NICE recommends a different approach. Patients with T2DM or GDM managed on lifestyle modifications, oral hypoglycemic agents (OHA) or single long-acting insulin injection need to measure fasting blood sugar and one hour post-prandially. More frequent monitoring is advisable for patients with T1DM, T2DM or GDM managed with multiple daily insulin injections: fasting, before and after meals and bedtime [5] (Table 3).

Glycemic targets: FPG and post-prandial glucose levels during the first trimester and first half of second trimester are normally lower than normal non-pregnant women. If high glucose readings are noted at this time, this could indicate PED [3]. All guidelines advise the same glycemic target for patients with both PED and GDM. They advise a FPG of less than $5.3 \mathrm{mmol} / \mathrm{L}$ and 1-hour postprandial glucose less than $7.8 \mathrm{mmol} / \mathrm{L}$. FIGO, the American and Canadian guidelines advise a target glucose 2 hours postprandial of less than $6.7 \mathrm{mmol} / \mathrm{L}$ while NICE recommends a value below $6.4 \mathrm{mmol} / \mathrm{L}[1,2,4-7,9]$ (Table 4). Some studies indicate that glucose levels post-prandially are more associated with macrosomia than fasting [6].

Hypoglycemia is common in pregnancy, especially in those with T1DM [7]. Hence, patients and their families should be educated on how to treat it [7]. HbAlc may be unreliable in pregnancy but it can help determine the accuracy of self-monitoring of blood glucose (SMBG) charting [6] (Table 3). HbAlc in pregnancy is lower than in non-pregnant women due to increased red blood cell turnover [4]. Maintaining an HbAlc of less than $6 \%$ in the second and third trimesters is associated with a lower risk of LGA and stillbirth $[7,9]$. However, HbA1c should be a secondary measure of glycemic control because it cannot identify patterns of hypo or hyperglycemia [7].

Antenatal follow up: NICE recommends assessing viability and confirming gestational age at 7-9 weeks [5]. ACOG and NICE advise an anomaly scan at around 20 weeks in addition to assessing the fetal heart [5,7]. Monitoring of fetal growth and amniotic fluid volume should be performed generally every $3-4$ weeks starting at 28 weeks and then weekly from 36 weeks $[1,5,7,9]$. This helps assess the effect of maternal glycemia on the fetus1. Also, fetal wellbeing investigations in the third trimester include non-stress test, amniotic fluid index, biophysical profile and maternal assessment of fetal movements [7]. In overweight and obese women, a weight gain of less than $5 \mathrm{~kg}$ during pregnancy is associated with a fetus small for gestational age (SGA), reduced neonatal fat mass and decreased head circumference [6]. Over-treating GDM can also possibly lead to SGA [1]. American and Canadian guidelines advise close monitoring of plasma glucose (PG) 
Table 2. Comparison of diabetes screening prenatally, antenatally and postnatally

\begin{tabular}{|c|c|c|c|c|c|c|}
\hline & KHUH & NICE & SOGC/CDA & ACOG/ADA & WHO & FIGO \\
\hline \multicolumn{7}{|c|}{ Prenatal/Antenatal Screening for Diabetes } \\
\hline Method & $75 \mathrm{~g}$ 2- hour OGTT* & $\begin{array}{c}\text { HbA1c } \\
75 \mathrm{~g} 2-\text { hour OGTT* }\end{array}$ & $\begin{array}{c}\text { HbA1c or FPG } \\
\text { 1 step: } 75 \mathrm{~g} \text { 2-hr OGTT* or } \\
2 \text { step: } 50 \mathrm{~g} \text { GCT and } 75 \mathrm{~g} \\
\text { 2-hr OGTT* }\end{array}$ & $\begin{array}{c}1 \text { step }(75 \mathrm{~g} 2 \text {-hr OGTT)* or } \\
2 \text { step }(50 \mathrm{~g} \text { GCT and } 100 \mathrm{~g} \\
\text { 3-hr OGTT)** }\end{array}$ & $75 \mathrm{~g} 2$ - hour OGTT* & $\begin{array}{l}\text { FPG, RPG, HbA1c } \\
75 \mathrm{~g} 2 \text { - hour OGTT* }\end{array}$ \\
\hline Timing & \multicolumn{4}{|c|}{$\begin{array}{l}\text { At booking } \\
24-28 \text { weeks }\end{array}$} & $24-28$ weeks & $\begin{array}{l}\text { At booking } \\
24-28 \text { weeks }\end{array}$ \\
\hline \multirow{3}{*}{$\begin{array}{l}\text { Diagnostic } \\
\text { Criteria }\end{array}$} & \multirow{3}{*}{$\begin{array}{l}\mathrm{FPG} \geq 5.1 \mathrm{mmol} / \mathrm{L} \\
\text { 1-hr postprandial } \mathrm{PG} \geq 10 \\
\mathrm{mmol} / \mathrm{L} \\
\text { 2-hr postprandial } \mathrm{PG} \geq 8.5 \\
\mathrm{mmol} / \mathrm{L}\end{array}$} & \multirow[b]{2}{*}{$\mathrm{FPG} \geq 5.6 \mathrm{mmol} / \mathrm{L}$} & \multicolumn{2}{|c|}{$\begin{array}{c}1 \text { step: } 75 \mathrm{~g} \text { OGTT } \\
\text { FPG } \geq 5.1 \mathrm{mmol} / \mathrm{L} \\
\text { 1-hr post prandial PG } \geq 10 \mathrm{mmol} / \mathrm{L} \\
\text { 2-hr post prandial } \mathrm{PG} \geq 8.5 \mathrm{mmol} / \mathrm{L}\end{array}$} & \multirow{3}{*}{\multicolumn{2}{|c|}{$\begin{array}{l}\text { DIP } \\
\text { FPG } \geq 7 \mathrm{mmol} / \mathrm{L} \\
2 \text {-hr postprandial } \geq 11.1 \mathrm{mmol} / \mathrm{L} \\
\mathrm{RPG} \geq 11.1 \mathrm{mmol} / \mathrm{L} \text { in the presence of diabetes } \\
\text { symptoms } \\
\text { HbA } 1 \mathrm{c} \geq 6.5 \% \\
\text { GDM } \\
\text { FPG } 5.1-6.9 \mathrm{mmol} / \mathrm{L} \\
\text { 1-hr post prandial PG } \geq 10 \mathrm{mmol} / \mathrm{L} \\
\text { 2-hr post prandial PG: } 8.5-11 \mathrm{mmol} / \mathrm{L}\end{array}$}} \\
\hline & & & $\begin{array}{l}\text { PED if } \mathrm{HbAlc} \geq 6.5 \% \text { or } \\
\text { FPG } \geq 7 \mathrm{mmol} / \mathrm{L} \\
2 \text { step: } 50 \mathrm{~g} \mathrm{GCT} \\
\text { Normal: } 1 \text {-hr post prandial } \\
\mathrm{PG}<7.8 \mathrm{mmol} / \mathrm{L}\end{array}$ & $\begin{array}{l}2 \text { step: } 50 \mathrm{~g} \text { GCT } \\
\text { IF } 1 \mathrm{hr} \text { post prandial } \mathrm{PG} \geq \\
7.8 \mathrm{mmol} / \mathrm{L}\end{array}$ & & \\
\hline & & $\begin{array}{l}\text { 2-hr post prandial } \mathrm{PG} \geq 7.8 \\
\mathrm{mmol} / \mathrm{L}\end{array}$ & $\begin{array}{l}\text { IF } 1 \mathrm{hr} \text { post prandial } \geq 7.8 \\
\mathrm{mmol} / \mathrm{L} \\
\text { THEN } 75 \mathrm{~g} \text { OGTT } \\
\text { Fasting } \geq 5.3 \mathrm{mmol} / \mathrm{L} \\
\text { 1-hr post prandial } \mathrm{PG} \geq 10.6 \\
\mathrm{mmol} / \mathrm{L} \\
\text { 2-hr post prandial } \mathrm{PG} \geq 9 \\
\mathrm{mmol} / \mathrm{L} \\
\text { GDM: } 1 \text {-hr post prandial } \\
\text { PG } \geq 11 \mathrm{mmol} / \mathrm{L}\end{array}$ & $\begin{array}{l}\text { THEN } 3 \text {-hr } 100 \mathrm{~g} \text { OGTT } \\
\text { FPG } 5.3 \leq \\
\text { 1-hr post prandial } 10 \leq \\
\text { 2-hr post prandial } 8.6 \leq \\
\text { 3-hr post prandial } 7.8 \leq \\
\end{array}$ & & \\
\hline \multicolumn{7}{|c|}{ Postnatal Screening for Diabetes } \\
\hline Timing & 6-12 weeks & $\begin{array}{l}6-13 \text { weeks } \\
\text { Or } 13 \text { weeks < }\end{array}$ & 6 weeks -6 months & $4-12$ weeks & 6 weeks $\leq$ & $6-12$ weeks \\
\hline Method & FPG & $\begin{array}{c}\text { FPG } \\
\text { Or FPG or } \mathrm{HbA} 1 \mathrm{c}\end{array}$ & \multicolumn{4}{|c|}{$75 \mathrm{~g} 2$ - hour OGTT* } \\
\hline $\begin{array}{l}\text { Diagnostic } \\
\text { Criteria }\end{array}$ & NA & $\begin{array}{l}\text { Normal } \\
\text { FPG }<6 \mathrm{mmol} / \mathrm{L} \text { or } \\
\mathrm{HbAl}<5.7 \% \\
\text { If FPG }>7 \mathrm{mmol} / \mathrm{L} \text {, then } \\
\text { check if HbAlc } \geq 6.5 \% \text {, } \\
\text { then this confirms T2DM }\end{array}$ & $\begin{array}{l}\text { Normal } \\
\text { FPG }<6.1 \mathrm{mmol} / \mathrm{L} \\
2 \text {-hr PG }<7.8 \mathrm{mmol} / \mathrm{L} \\
\mathrm{HbA} 1 \mathrm{c}<6 \% \\
\text { Pre-diabetes } \\
\text { FPG } 6.1-6.9 \mathrm{mmol} / \mathrm{L} \\
\text { 2-hr PG: } 7.8-11.1 \mathrm{mmol} / \mathrm{L} \\
\mathrm{HbAlc} 6-6.4 \% \\
\text { T2DM } \\
\text { FPG } \geq 7 \mathrm{mmol} / \mathrm{L} \\
2 \text {-hr PG } \geq 11.1 \mathrm{mmol} / \mathrm{L} \\
\text { RPG } \geq 11.1 \mathrm{mmol} / \mathrm{L} \\
\mathrm{HbA} 1 \mathrm{c}>6.5 \%\end{array}$ & $\begin{array}{l}\text { Normal } \\
\mathrm{FPG}<5.5 \mathrm{mmol} / \mathrm{L} \\
2-\mathrm{hr} \mathrm{PG}<7.8 \mathrm{mmol} / \mathrm{L} \\
\text { Impaired fasting glucose } \\
\pm \quad \text { Impaired glucose } \\
\text { tolerance } \\
\text { FPG } 5.5-6.9 \mathrm{mmol} / \mathrm{L} \\
\text { 2-hr PG: } 7.8-11.1 \mathrm{mmol} / \mathrm{L} \\
\text { T2DM } \\
\text { FPG }>6.9 \mathrm{mmol} / \mathrm{L} \\
\text { 2-hr PG }>11.1 \mathrm{mmol} / \mathrm{L}\end{array}$ & $\begin{array}{l}\text { Normal } \\
\text { FPG }<6.1 \mathrm{mmol} / \mathrm{L} \\
2-\mathrm{hr} \text { PG }<7.8 \mathrm{mmol} / \mathrm{L} \\
\text { Impaired fasting glucos } \\
\text { FPG } 6.1-6.9 \mathrm{mmol} / \mathrm{L} \\
\text { 2-hr PG }<7.8 \mathrm{mmol} / \mathrm{L} \\
\text { Impaired glucose tolera } \\
\text { FPG }<7 \mathrm{mmol} / \mathrm{L} \\
\text { 2-hr PG: } 7.8-11.1 \mathrm{mmol} / 1 \\
\text { T2DM } \\
\text { FPG } \geq 7 \mathrm{mmol} / \mathrm{L} \\
2-\mathrm{hr} \text { PG } \geq 11.1 \mathrm{mmol} / \mathrm{L}\end{array}$ & \\
\hline
\end{tabular}

levels and adjusting insulin doses accordingly if a woman receives antenatal corticosteroids to avoid hyperglycemia, diabetic ketoacidosis and possibly fetal death $[1,2,4,5,7,9]$. Antenatal corticosteroids could be administered for tocolysis or fetal lung maturation [5,9]. ACOG recommends reviewing SMBG records every 1-2 weeks during the first two trimesters and then weekly in the third trimester [2,7]. Table 4 summarizes recommendations on antenatal care.

Management of PED: NICE, ADA, ACOG, SOGC and CDA advise switching from OHA to insulin $[1,4,5,7,9]$. Insulin does not cross the placenta. OHA are ineffective in T1DM and cannot overcome insulin resistance in T2DM [4]. Metformin can either be an adjunct or an alternative $[4,5,7]$. They also advise starting aspirin at 12 weeks gestation as prophylaxis against pre-eclampsia $[1,4,5,7,9]$. Women at high risk of developing PET include those with PED, chronic hypertension, chronic kidney disease and previous hypertension during pregnancy $[4,5]$. PET occurs more often in patients with chronic hypertension and poor glucose control [7]. CDA also recommends calcium supplements of more than $1000 \mathrm{mg}$ per day as protective against pre-eclampsia [9]. NICE recommends thromboprophylaxis for those with proteinuria of more than $5 \mathrm{~g}$ per day [5] (Table 5). ADA recommends methyldopa, labetalol and nifedipine as non-teratogenic medications against hypertension in pregnancy [4]. Patients with T1DM need ketone strips and a ketone meter to detect ketosis $[4,5]$.

Management of GDM: $70-85 \%$ of patients with GDM can be managed with lifestyle changes, thus making it the mainstay of treatment $[4,6]$. FIGO recommends medical nutrition therapy (MNT) as the first 
Table 3. Comparison of glycemic targets amongst guidelines

\begin{tabular}{|c|c|c|c|c|c|}
\hline & KHUH & NICE & SOGC/CDA & ACOG/ADA & FIGO \\
\hline \multicolumn{6}{|l|}{ Preconception } \\
\hline $\begin{array}{l}\text { G l y c e m i c } \\
\text { Target }\end{array}$ & $\begin{array}{l}\text { HbAlc }<6.1 \% \\
\text { FPG } 3.5-5.9 \mathrm{mmol} / \mathrm{L} \\
1-\mathrm{hr} \text { postprandial }<7.8 \mathrm{mmol} / \mathrm{L}\end{array}$ & $\begin{array}{l}\text { HbA1c }<6.5 \% \\
\text { FPG } 5-7 \mathrm{mmol} / \mathrm{L} \\
\text { Pre-prandial } 4-7 \mathrm{mmol} / \mathrm{L}\end{array}$ & $\begin{array}{l}\mathrm{HbA} 1 \mathrm{c} \leq 6.5 \% \text { or } \leq 7 \% \\
\text { (if hypoglycemia) }\end{array}$ & $\begin{aligned} \mathrm{HbA} 1 \mathrm{c} & <6 \% \quad(\mathrm{ACOG}) \\
& <6.5 \%(\mathrm{ADA})\end{aligned}$ & NA \\
\hline Monitoring & NA & $\begin{array}{l}\text { SMBG 4-7 times daily } \\
\text { Monthly HbA1c }\end{array}$ & \multicolumn{3}{|c|}{ NA } \\
\hline \multicolumn{6}{|l|}{ Antenatal } \\
\hline \multirow{3}{*}{$\begin{array}{l}\text { G l y c e m i c } \\
\text { Target }\end{array}$} & \multirow{3}{*}{$\begin{array}{l}\mathrm{FPG}<5 \mathrm{mmol} / \mathrm{L} \\
2 \text {-hr post prandial }<6.7 \mathrm{mmol} / \mathrm{L}\end{array}$} & \multirow{3}{*}{$\begin{array}{l}\mathrm{FPG}<5.3 \mathrm{mmol} / \mathrm{L} \\
1 \mathrm{hr} \text { post prandial }<7.8 \mathrm{mmol} / \mathrm{L} \\
2 \mathrm{hr} \text { post prandial }<6.4 \mathrm{mmol} / \mathrm{L}\end{array}$} & $\begin{array}{c}\mathrm{HbA} 1 \mathrm{c} \leq 6.1 \% \text { or } \leq 6.5 \% \text { (if } \\
\text { hypoglycemia) }\end{array}$ & $\begin{array}{l}\mathrm{HbA} 1 \mathrm{c}<6 \% \text { or }<7 \% \\
\text { (if hypoglycemia) }\end{array}$ & NA \\
\hline & & & \multicolumn{3}{|c|}{$\begin{array}{c}\mathrm{FPG}<5.3 \mathrm{mmol} / \mathrm{L} \\
1-\mathrm{hr} \text { post prandial }<7.8 \mathrm{mmol} / \mathrm{L} \\
2-\mathrm{hr} \text { post prandial }<6.7 \mathrm{mmol} / \mathrm{L}\end{array}$} \\
\hline & & & NA & $\begin{array}{l}\text { Bedtime }>3.3 \mathrm{mmol} / \mathrm{L} \\
\text { Average } 5.6 \mathrm{mmol} / \mathrm{L}\end{array}$ & NA \\
\hline Monitoring & NA & $\begin{array}{l}\text { T1DM/T2DM/GDM } \\
\text { multiple insulin injections: } \\
\text { - SMBG } 8 \text { times/day } \\
\text { T2DM/GDM on lifestyle } \\
\text { modifications or OHA: } \\
\text { - SMBG } 4 \text { times/day }\end{array}$ & \multicolumn{2}{|l|}{$\begin{array}{l}\text { PED: SMBG 4-7 times/day } \\
\text { GDM: SMBG 3-4 times/day }\end{array}$} & $\begin{array}{l}\text { SMBG - 3-4 times/day } \\
\text { Low resource setting: once per } \\
\text { day }\end{array}$ \\
\hline \multicolumn{6}{|l|}{ Intrapartum } \\
\hline $\begin{array}{l}\text { G l y c e m i c } \\
\text { Target }\end{array}$ & \multicolumn{3}{|c|}{$4-7 \mathrm{mmol} / \mathrm{L}$} & $<6.1 \mathrm{mmol} / \mathrm{L}$ & $4-7 \mathrm{mmol} / \mathrm{L}$ \\
\hline Monitoring & \multicolumn{2}{|c|}{ Hourly } & Close monitoring & Hourly & NA \\
\hline
\end{tabular}

Abbreviations: NA: not applicable; HbA1c: glycosylated hemoglobin; FPG: fasting plasma glucose; SMBG: self-monitoring of blood glucose; T1DM: type 1 diabetes mellitus; T2DM: type 2 diabetes mellitus; GDM: gestational diabetes mellitus; OHA: oral hypoglycemic agents; PED: pre-existing diabetes

Table 4. Antenatal care

\begin{tabular}{|c|c|c|c|c|c|}
\hline & KHUH & NICE & SOGC/CDA & ACOG & FIGO \\
\hline Viability & \multicolumn{2}{|c|}{ Confirm gestational age and viability at $7-9$ weeks } & \multicolumn{3}{|c|}{ NA } \\
\hline Anomaly Scan & \multicolumn{2}{|c|}{20 weeks } & NA & $18-20$ weeks & NA \\
\hline $\begin{array}{l}\text { Fetal Growth and Amniotic } \\
\text { Fluid Volume }\end{array}$ & \multicolumn{2}{|c|}{$\begin{array}{c}28-36 \text { weeks } \\
\text { Ultrasound monitoring every } 4 \text { weeks }\end{array}$} & $\begin{array}{l}\text { 28-36 weeks } \\
\text { Every 3-4 weeks }\end{array}$ & $34-38+6$ weeks & $\begin{array}{l}\text { Every 2-4 weeks from } \\
\text { diagnosis until term }\end{array}$ \\
\hline Fetal Wellbeing Tests & \multicolumn{2}{|c|}{38 weeks until delivery } & 36 weeks until delivery & $3^{\text {rd }}$ trimester & $\begin{array}{l}\text { Non-stress test, biophysical } \\
\text { profile }\end{array}$ \\
\hline $\begin{array}{l}\text { Corticosteroid } \\
\text { Administration }\end{array}$ & \multicolumn{2}{|c|}{ Adjust insulin dose if administering antenatal corticosteroids } & $\begin{array}{l}\text { Increase insulin doses over } \\
\text { the next } 7 \text { days }\end{array}$ & $\begin{array}{l}\text { Increase insulin doses over } \\
\text { next } 5 \text { days }\end{array}$ & NA \\
\hline Others & $\begin{array}{c}\text { Review SMBG, vital signs, } \\
\text { weight and urinalysis in each } \\
\text { antenatal visit }\end{array}$ & NA & $\begin{array}{c}\text { Umbilical artery and middle } \\
\text { cerebral Doppler if suspecting } \\
\text { SGA }\end{array}$ & $\begin{array}{l}\text { Fetal echocardiography if } \\
\text { suspecting cardiac defects }\end{array}$ & $\begin{array}{l}\text { Weight, blood pressure and } \\
\text { urine dipstick for protein } \\
\text { every } 1-2 \text { weeks }\end{array}$ \\
\hline
\end{tabular}

Abbreviations: NA: not applicable; SMBG: self-monitoring of blood glucose; SGA: small for gestational age

line of treatment for GDM. MNT is a "carbohydrate-controlled meal plan that promotes adequate nutrition with appropriate weight gain, normoglycemia and the absence of ketosis" [6]. NICE and SOGC/ CDA recommend a trial of lifestyle modifications for 1-2 weeks and if this fails, NICE recommends starting metformin while SOGC/CDA recommend starting insulin (Table 6). In fact, up to $40 \%$ of patients taking metformin need added insulin [9].

OHA are known to cross the placenta; however, there is no longterm evidence available regarding their safety [6]. Metformin can be an alternative. Additionally, metformin is considered superior to glyburide. Glyburide is considered if insulin, metformin or both achieve inadequate glycemic control [1,9]. However, glyburide is associated with a higher risk of neonatal hypoglycemia and macrosomia compared to insulin and metformin [4].

According to NICE, if there is macrosomia, polyhydramnios or FPG greater than $7 \mathrm{mmol} / \mathrm{L}$ then the patient should directly be started on insulin with or without OHA. Insulin is also the first line of pharmacological therapy as per ACOG/ADA and FIGO [2,4,6] (Table 6).
Time and mode of delivery: During delivery, it is essential to maintain glycemic control. ACOG advises keeping readings below 6.1 $\mathrm{mmol} / \mathrm{L}$ while NICE, FIGO and the Canadian guidelines recommend readings between 4 and $7 \mathrm{mmol} / \mathrm{L}$ [5-7,9] (Table 3). This was found to reduce birth asphyxia, maternal and neonatal hypoglycemia $[6,9]$. Intravenous dextrose and insulin can help maintain such levels, particularly in T1DM and poor glucose control. Avoiding maternal hyperglycemia can help prevent fetal hyperglycemia thus reducing neonatal hypoglycemia [7]. Women with poorly controlled diabetes are predisposed to having a baby with a disproportionate deposition of fat around the shoulders and chest which doubles the risk of shoulder dystocia during vaginal delivery [7]. It is important to note that there is a $15 \%$ error margin associated with fetal growth as assessed by ultrasonography [6]. Induction of labor can help reduce excess fetal growth, shoulder dystocia and Cesarean section [9]. If estimated fetal weight is greater than $4.5 \mathrm{~kg}$, a prophylactic Cesarean section is indicated as per ACOG [7].

For patients with PED, delivery depends on the presence of complications. Besides the American guidelines, NICE and Canadian 
Table 5. Management of diabetes (PED AND GDM)

\begin{tabular}{|c|c|c|c|c|c|}
\hline & KHUH & NICE & SOGC/CDA & ACOG/ADA & FIGO \\
\hline \multicolumn{6}{|l|}{ Pre-Existing Diabetes } \\
\hline \multirow{3}{*}{$\begin{array}{l}\text { Pharmacological } \\
\text { Therapy }\end{array}$} & \multirow[b]{3}{*}{ NA } & \multicolumn{3}{|c|}{ Switch from OHA to insulin } & \multirow{6}{*}{ NA } \\
\hline & & Metformin: adjunct or alternative & & $\begin{array}{l}\text { First line: insulin } \\
\text { Metformin: adjunct or alternative } \\
\text { in T2DM }\end{array}$ & \\
\hline & & $\begin{array}{l}\text { Aspirin } 75-150 \mathrm{mg} \text { (12 weeks } \\
\text { until delivery) } \\
\text { Thromboprophylaxis } \\
\text { (if proteinuria }>5 \mathrm{~g} / \text { day })\end{array}$ & $\begin{array}{l}\text { Aspirin } 81 \mathrm{mg} \text { (12 weeks until } \\
\text { delivery) } \\
\text { Calcium supplements > } \\
1000 \mathrm{~g} / \text { day }\end{array}$ & $\begin{array}{l}\text { Aspirin } 60-150 \mathrm{mg} \text { (ACOG: } 81 \\
\mathrm{mg})(12 \text { weeks until delivery) }\end{array}$ & \\
\hline \multirow{3}{*}{ Postnatal } & \multicolumn{4}{|c|}{ Return to pre-pregnancy insulin doses } & \\
\hline & \multirow{2}{*}{$\begin{array}{l}\text { Administer long-acting } \\
\text { insulin before stopping insulin } \\
\text { infusion }\end{array}$} & \multicolumn{3}{|c|}{ Frequent SMBG } & \\
\hline & & $\begin{array}{l}\text { Avoid teratogenic medication } \\
\text { while breastfeeding }\end{array}$ & Lifestyle counseling & NA & \\
\hline \multicolumn{6}{|c|}{ Gestational Diabetes Mellitus } \\
\hline Lifestyle & \multicolumn{3}{|c|}{ 1-2 week trial of diet and exercise } & \multicolumn{2}{|c|}{30 minutes of exercise daily } \\
\hline $\begin{array}{l}\text { Medical Nutrition } \\
\text { Therapy }\end{array}$ & \multicolumn{3}{|c|}{ NA } & $\begin{array}{c}\text { Minimum/day: } \\
\text { 175g carbohydrates } \\
71 \mathrm{~g} \text { protein } \\
28 \mathrm{~g} \text { fiber } \\
\text { Carbohydrates } 40 \% \\
\text { Fat } 40 \% \text { Protein } 20 \%\end{array}$ & $\begin{array}{l}\text { First line of treatment } \\
\text { Minimum } 175 \mathrm{~g} \text { of } \\
\text { carbohydrates per day }\end{array}$ \\
\hline $\begin{array}{l}\text { Pharmacological } \\
\text { Therapy }\end{array}$ & Refer to endocrinology & $\begin{array}{l}\text { Metformin if } \mathrm{FPG}<7 \mathrm{mmol} / \mathrm{L} \\
\text { Insulin if } \mathrm{FPG} \geq 7 \mathrm{mmol} / \mathrm{L}, \\
\text { polyhydramnios or macrosomia } \\
\text { Alternative: glyburide }\end{array}$ & \multicolumn{3}{|c|}{$\begin{array}{l}\text { First line: insulin } \\
\text { Alternatives: metformin, glyburide }\end{array}$} \\
\hline Postnatal & \multicolumn{2}{|c|}{$\begin{array}{l}\text { Stop anti-diabetic medication } \\
\text { Offer lifestyle advice }\end{array}$} & \multicolumn{3}{|c|}{ Lifestyle advice } \\
\hline
\end{tabular}

Abbreviations: NA: not applicable; PED: pre-existing diabetes; OHA: oral hypoglycemic agents; T2DM: type 2 diabetes mellitus; SMBG: self-monitoring of blood glucose; GDM: gestational diabetes mellitus

Table 6. Comparison of recommendations on delivery

\begin{tabular}{|c|c|c|c|c|c|}
\hline & NICE & SOGC/CDA & KHUH & ACOG & FIGO \\
\hline \multicolumn{6}{|l|}{ PED } \\
\hline With Complications & Before 37 weeks & \multicolumn{2}{|c|}{ IOL before 38 weeks } & $\begin{array}{c}\text { IOL at } 36-38+6 \text { weeks } \\
\text { or earlier }\end{array}$ & \multirow{2}{*}{ NA } \\
\hline Without Complications & IOL/ELCS at $37-38+6$ weeks & \multicolumn{2}{|c|}{ IOL at 38-39 weeks } & IOL at $39-39+6$ weeks & \\
\hline \multicolumn{6}{|l|}{ GDM } \\
\hline On Lifestyle Management & & IOL at 40 weeks & IOL at $39-40+6$ weeks & $\begin{array}{l}\text { Expectant management up to } \\
440+6 \text { weeks }\end{array}$ & \multirow[b]{2}{*}{$\begin{array}{l}\text { IOL at } 38-39 \text { weeks if } \\
\text { - EFW } 3.8-4 \mathrm{~kg} \text { or LGA } \\
-\quad \text { Poorly controlled or } \\
\text { complications present } \\
\text { ELCS at } 38-39 \text { weeks if EFW } \\
>4000 \mathrm{~g} \\
\text { IOL at } 40-41 \text { weeks if no } \\
\text { complications }\end{array}$} \\
\hline $\begin{array}{l}\text { On Pharmacological } \\
\text { Management }\end{array}$ & $\begin{array}{c}\text { IOL/ELCS before } \\
40+6 \text { weeks }\end{array}$ & IOL at 39 weeks & \multicolumn{2}{|c|}{$\begin{array}{l}\text { Failed in-hospital glycemic control or } \\
\text { Abnormal fetal testing: } \\
34-36+6 \text { weeks } \\
\text { Poorly controlled: } \\
37-38+6 \text { weeks } \\
\text { Well-controlled: } \\
39-39+6 \text { weeks } \\
\text { Prophylactic ELCS if } \\
\text { EFW } \geq 4.5 \mathrm{~kg}\end{array}$} & \\
\hline
\end{tabular}

Abbreviations: NA: not applicable; PED: pre-existing diabetes; GDM: gestational diabetes mellitus IOL: induction of labor; ELCS: elective Cesarean section; EFW: estimated fetal weight

guidelines advise delivery before 39 weeks $[1,5,9]$. On the other hand, delivery of patients with GDM mostly depends on their management. Delivery is generally advised before 41 weeks. Those managed on medication are advised an earlier delivery than those managed on lifestyle changes. However, FIGO does not consider the management a patient receives. FIGO advises an earlier delivery if complications present [6]. And NICE considers neither the presence of complications nor the type of management. They simply advise delivery before $40+6$ weeks of gestation [5] (Table 6).

Neonatal care: Only NICE mentioned recommendations regarding the management of infants of diabetic mothers. They advise diabetic mothers to deliver in tertiary healthcare centers that include a neonatal intensive care unit (NICU) and possess advanced skills in neonatal resuscitation. Feeding is advised within 30 minutes of delivery and then every 2-3 hours while maintaining the baby's PG above 2 $\mathrm{mmol} / \mathrm{L}$. Blood glucose testing should be performed 2-4 hours after birth. Intravenous dextrose is reserved for neonates demonstrating signs of hypoglycemia. They should be tested for polycythemia, hyperbilirubinemia, hypocalcemia and hypomagnesemia. Babies should be admitted to the NICU if they demonstrate any signs of respiratory distress, hypoglycemia, cardiac decompensation, neonatal encephalopathy or jaundice. Ultimately, they should not be discharged until they are at least 24 hours of age [5]. 
Postnatal care: After delivery of patients with PED, it is important to instantly reduce insulin doses to pre-pregnancy doses to avoid the risk of hypoglycemia [9]. Breastfeeding is highly recommended amongst the guidelines $[1,5-7,9]$. It is protective against both maternal and infant complications. It helps reduce the risk of childhood obesity, T1DM and T2DM in the child and helps with maternal weight loss [1,6,9]. WHO does not mention any recommendations regarding breastfeeding. Diabetic mothers are more prone to infections and therefore need extra attention postnatally [6]. A follow up test for GDM is mostly 2-hour 75 g OGTT. NICE does not recommend the use of OGTT. Instead, they advise FPG at 6-13 weeks after delivery or either FPG or HbA1c at 13 weeks onwards [5] (Table 2). According to ACOG and ADA, OGTT is more sensitive to glucose intolerance than $\mathrm{HbAlc}[2,4]$. Studies prove that those with GDM in a previous pregnancy are at a higher risk of developing DM postnatally compared to those who have had it for the first time [6]. ADA notes that metformin and lifestyle changes can possibly delay progression to diabetes or even prevent it [4].

Contraception: The choice of contraception mainly depends on the patient's choice and presence of complications [5]. Contraception containing estrogen is contra-indicated in patients who are breastfeeding, have hypertension or vascular complications. Hence, progestin-only, implantable progestin or intra-uterine device may be more appropriate [7,9]. Otherwise, patients who do not smoke and do not have vascular complications can safely use combined oral contraceptive pills, as per ACOG [7] (Table 1).

\section{Summary of current guidelines}

\section{NICE guidelines}

During preconception counseling for PED, patients should be educated regarding the risks associated with pregnancy, importance of glucose level control and the use of contraception. Babies who have the potential to develop hypoglycemia, might require admission to the NICU and can possibly develop obesity and consequent T2DM. Glycemic control can help avoid congenital malformations and reduce the risk of miscarriage, stillbirth and neonatal death. Glucose monitoring should be intensified in cases of inadequate control (Table $3)$. Effective contraception can help prevent unplanned pregnancies. Contraception can be stopped once glycemic control has been achieved. OCPs can be used if there are no contraindications. Renal and retinal assessment is crucial for patients with PED to detect any existing comorbidities (Table 1). T1DM patients should be provided with ketone blood strips and ketone meter to test for diabetic ketoacidosis in addition to glucagon [5].

Patients should be screened for PED at booking with HbA1c. If a patient has a previous history of GDM, then they should be screened with an OGTT at booking and repeat it at 24-28 weeks. They should also be screened at 24-28 weeks if they have one or more risk factor (Table 2). Those diagnosed with GDM are advised to eat foods with low glycemic index and 30 minutes of exercise. If this fails, then should be started on either metformin or insulin, depending on their FPG at diagnosis (Table 5). Table 3 demonstrates recommendations on glycemic targets. NICE proposes stricter monitoring of PG levels for patients with T1DM, T2DM or GDM receiving multiple insulin injections compared to those on lifestyle management or single longacting insulin. They are advised to monitor levels fasting, before and after meals and at bedtime. If patients are on glyburide or insulin, they should aim to keep PG above $4 \mathrm{mmol} / \mathrm{L}$ [5].

NICE does not consider diabetes as a contraindication for vaginal birth after Cesarean. Postnatally, if a woman with GDM screened normal, then she should measure HbAlc annually. If her FPG measures between 6-6.9 mmol/L, she should be advised that she is at high risk of developing T2DM and she should make lifestyle changes. If her results are diagnostic of T2DM, she should be referred to an endocrinologist for further management [5] (Table 2).

\section{WHO guidelines}

Hyperglycemia in pregnancy should be classified as either diabetes in pregnancy (DIP) or gestational diabetes mellitus (GDM). Table 2 demonstrates the diagnostic criteria for each classification. DIP can be diagnosed at any time during pregnancy. Screening for GDM is reserved for those with risk factors. GDM should be managed with lifestyle changes, including nutritional counseling and exercise, in addition to OHA or insulin. WHO mentions that those with PED require increased monitoring of blood glucose levels during pregnancy. Otherwise, patients with GDM must measure blood sugar both fasting and after meals [3].

Women with GDM or impaired fasting glucose during pregnancy should be screened with $75 \mathrm{~g}$ OGTT at 6 weeks or more after delivery. They should then be classified as normal glucose tolerance, impaired fasting glucose, impaired glucose tolerance or DM [3] (Table 3).

WHO does not give any recommendations on preconception care, antenatal care or glycemic targets. Their guidelines simply concentrate on the classification, screening and diagnosis of hyperglycemia in pregnancy.

\section{American (ACOG/ADA) guidelines}

ACOG guidelines: Patients should be informed of the risks associated with conceiving. They should use contraception until they achieve euglycemic control [7]. Recommended contraception methods [7] are displayed in Table 1. The aim is to achieve euglycemia by implementing lifestyle changes and administering medical therapy without hypoglycemia [7]. In case diet and exercise fail to maintain glycemic control, then insulin is the preferred medical treatment, since metformin is associated with increased treatment failure with a possible need for supplementation with insulin [2,7] (Table 5). Unlike those with GDM, patients with PED are advised to check PG levels before meals. They should also aim for an average PG of $5.6 \mathrm{mmol} / \mathrm{L}$ and a bedtime reading of more than $3.3 \mathrm{mmol} / \mathrm{L}$ [7] (Table 3).

Fetal echocardiography can be performed when suspecting cardiac defects. Expectant management, for patients with PED, is not advisable beyond 40 weeks of gestation [7]. If postnatal screening for diabetes is normal, then a patient should undergo screening every 1-3 years depending on risk factors. If she has either impaired fasting glucose or impaired glucose tolerance then she should be referred for weight loss, exercise, metformin if she has both and yearly assess her glycemic status. If she is diagnosed with T2DM, she should be referred for diabetes management [2] (Table 2).

ADA guidelines: Prenatally, women should be counseled regarding the importance of using contraception until glycemic control is achieved. They should be informed that pregnancy loss in T1DM is more common in the first trimester while it is more common in the third trimester in T2DM. They must undergo serology for HIV, rubella, hepatitis B and blood typing. Women should understand the possibility of progression of DR during their pregnancy and should regularly undergo retinal assessment (Table 1 ). If metformin was initially used for treating PCOS, it should be discontinued once pregnancy is confirmed [4]. 
Screening for DM with one of two methods at booking in the presence of risk factors and repeat at 24-28 weeks (Table 2). When the two-method is used at booking and a patient needs to be screened again, they can directly proceed with the second step without repeating the first step. Glycemic targets displayed in Table III might be difficult for patients with T1DM to meet. For hypertensive patients with PED, target systolic and diastolic blood pressures are 120-160 $\mathrm{mmHg}$ and 80-105 mmHg, respectively [4]. A lower blood pressure can possibly impair fetal growth. ADA does not offer any recommendations regarding antenatal care or the time and mode of delivery. Women with GDM should undergo testing postnatally $[4,10]$ diagnostic values are displayed in Table 2. And all contraception options are available for women [4].

\section{Canadian (SOGC/CDA) guidelines}

SOGC guidelines: Screening for GDM is generally advised at 24-28 weeks; however, women can be also be screened for DM in the following conditions:

- Earlier in the presence of risk factors

- Before administration of antenatal corticosteroids or 7 days after

- Later when suspecting late-onset GDM [1]

Testing women for diabetes less than 7 days after corticosteroid administration leads to abnormal testing in $48 \%$ of women. 28 weeks is the baseline for which fetal growth assessment and amniotic fluid volume is based on. Patients suspected of SGA could undergo Doppler study of umbilical and middle cerebral arteries. Postpartum, women diagnosed with pre-diabetes or diabetes should be referred for prevention and management with lifestyle counseling and medication if needed [1] (Table 2).

CDA guidelines: HbAlc or FPG should be measured at booking if there are risk factors for T2DM. If screening was negative at booking, it still needs to be repeated at 24-28 weeks. For those with PED, both aspirin and calcium supplements are thought to be prophylactic against PET [9]. Table 3 demonstrates recommendations on glycemic targets, which are the same for both PED and GDM. Patients with PED are advised a stricter glycemic monitoring compared to those with GDM. If diet and exercise fail to meet glycemic targets, then pharmacological treatment should be initiated (Table 5). Those on insulin should aim to keep PG above $3.7 \mathrm{mmol} / \mathrm{L}$. If a woman received antenatal corticosteroids, then insulin doses should be increased as follows:

- Day 1: increase night insulin by $25 \%$

- Days 2-3: increase all insulin doses by $40 \%$

- Day 4: increase all insulin doses by $20 \%$

- Day 5: increase all insulin doses by $10-20 \%$

- Days 6-7: gradually taper insulin doses to pre-corticosteroid doses [9]

For PED, delivery is not advised beyond 39 weeks while for GDM, delivery is advised up to 40 weeks (Table 5). Breastfeeding is advised for a minimum of 4 months. After delivery, women with T1DM should screen for postpartum thyroiditis with TSH 2-4 months postpartum. Table 1 demonstrates contraception options; absolute or relative contraindications to estrogen include breastfeeding, hypertension, microvascular or macrovascular complications of diabetes [9].

\section{FIGO guidelines}

The classification and diagnostic criteria of hyperglycemia in pregnancy are the same as WHO (Table 2). Screening for diabetes based on the level of resources in a setting is as follows:

- Fully Resourced Setting

o DIP: Measure FPG, RPG or HbA1c at booking

o GDM: Perform $75 \mathrm{~g}$ OGTT at 24-28 weeks if negative screening at booking

- Fully Resourced Setting with Ethnic Populations at High Risk

o DIP: Perform $75 \mathrm{~g}$ OGTT at booking

o GDM: Repeat $75 \mathrm{~g}$ OGTT at 24-28 weeks if negative screening at booking

- Medium-Low Resourced Setting with Ethnic Populations at Risk

o 24-28 weeks: Perform 75 g OGTT [6]

During pregnancy, women are advised to monitor PG levels fasting and post-prandially giving a total of 3-4 times daily; women in low resource settings can monitor levels once daily (Table 3 ). Patients and their families should be taught how to recognise hypoglycemia and how to quickly treat it. Patients with GDM are advised to eat food with low glycemic index. Carbohydrates should form $35-45 \%$ of the total calories. In those with diabetic nephropathy, protein intake should be reduced to $0.6-0.8 \mathrm{~g} / \mathrm{kg}$. 30 minutes of exercise in the form of a brisk walk or arm exercises while seated are recommended. In case lifestyle changes cannot help reach glycemic targets, physicians can rely on pharmacological treatment [6] (Table 5).

Insulin is considered the first line of treatment if one of the following:

- Diagnosis of $\mathrm{DM}<20$ weeks gestation

- Need for pharmacological therapy after 30 weeks

- $\mathrm{FPG}>6.1 \mathrm{mmol} / \mathrm{L}$

- 1-hour post-prandial PG $>7.8 \mathrm{mmol} / \mathrm{L}$

- Pregnancy weight gain $>12 \mathrm{~kg}$ [6]

FIGO does not include any recommendations regarding the management of patients with PED. Recommendations on delivery depend on the presence of complications and the extent of glycemic control (Table 6). Table 2 demonstrates the tests and diagnostic criteria for DM during pregnancy and postnatally. Contraception can help space out pregnancies to help reduce risk of developing GDM in future pregnancies [6].

\section{KHUH guidelines}

Prenatally, women should be counseled on the importance of glycemic control and the risks associated with pregnancy, which differ depending on the trimester. Miscarriages and congenital malformations tend to occur in the first trimester. A woman in the second trimester might experience preterm labor or undergo induction of labor (IOL) for PET. In the third trimester, there can be IUGR, macrosomia or fetal death. Also, during delivery, the mother is prone to birth trauma and increased risk of undergoing Cesarean section. A patient's medication, including those for co-morbidities of DM, should also be reviewed. Prior to conception, it is advised to perform retinal and renal assessment in addition to TSH and ECG [11] (Table 1). 
Regarding the prenatal care offered to patients with PED, most guidelines, including $\mathrm{KHUH}$, advise educating women about the risks associated with pregnancy and the importance of optimizing glucose control prior to conception. However, KHUH does not give any suggestions on possible contraceptive methods. KHUH advises stopping ACEIs and statins but they did not mention ARBs, which are commonly used as anti-hypertensives. KHUH follows NICE's recommendations on retinal assessment but only include establishing a baseline for renal assessment [11].

KHUH proposes the same diagnostic criteria as those by the one-step diagnostic test as advised by the American and Canadian guidelines. KHUH has the strictest glycemic targets both prenatally and during pregnancy. When screening for GDM, OGTT should be stopped if FPG or 1-hour post-prandial glucose are diagnostic of GDM. Women with PED do not need to be screened for DM antenatally. Diagnostic criteria for diabetes and glycemic targets, as proposed by IADPSG, are displayed in Tables 2 and 3. However, they do not specify the frequency of monitoring required by both those with PED and GDM. Glucose control should be performed on an outpatient basis; however, if that fails, a patient can be admitted for blood sugar control [11].

KHUH follows NICE's recommendations on antenatal care. Lifestyle management, for patients with GDM, is advised for two weeks. Beta-mimetics should be avoided in preterm labor. With regards to delivery, KHUH follows recommendations by both the Canadian and American guidelines. Progress of labor should be assessed every 2 hours. KHUH follows ACOG in advocating a prophylactic Cesarean section if estimated fetal weight exceeds $4.5 \mathrm{~kg}$ or there is a history of shoulder dystocia [7]. Patients with GDM are advised to screen for DM after delivery [11] (Table 2). KHUH does not mention the diagnostic criteria for testing patients with GDM postnatally.

Our institute's guidelines on diabetes in pregnancy can be improved by including a more robust list of medications that should be stopped, being more specific regarding end-organ assessment, specifying the antenatal frequency of glucose level monitoring for diabetic mothers, recommending a patient specific OHA/insulin regimen, options for prophylaxis against $\mathrm{PET}$, and advising on contraceptive methods.

\section{Conclusion}

By providing a comparison of seven major obstetric guidelines and our institute's guidelines regarding diabetes in pregnancy, this helps to shed light on similarities, differences, and important details that we can continue to develop as a specialty. In the context of Bahrain and the increasing prevalence of GDM, it is particularly valuable to ensure that local practices are consistent with international guidelines.

\section{References}

1. Berger H, Gagnon R, Sermer M (2019) Guideline No. 393-Diabetes in pregnancy. $J$ Obstet Gynaecol Can 41: 1814-1825. [Crossref]

2. Caughey AB, Turrentine M (2018) ACOG Practice bulletin No. 190: Gestational Diabetes Mellitus. Obstet Gynecol 131: e49-e64. [Crossref]

3. World Health Organization (2013) Diagnostic criteria and classification of Hyperglycemia first detected in pregnancy. Geneva: World Health Organization.

4. American Diabetes Association. Management of diabetes in pregnancy: Standards of medical care in diabetes-2019. Diabetes Care 42: S165-S172. [Crossref]

5. National Collaborating Centre for Women's and Children's Health (UK) (2015) Diabetes in Pregnancy: Management of diabetes and its complications from preconception to the postnatal period.

6. Hod M, Kapur A, Sacks DA, Hadar E, Agarwal M, et al. (2015) The international federation of gynecology and obstetrics (FIGO) Initiative on gestational diabetes mellitus: A pragmatic guide for diagnosis, management, and care. Int $J$ Gynaecol Obstet 131: S173-211. [Crossref]

7. American College of Obstetricians and Gynecologists' Committee on Practice Bulletins-Obstetrics (2018) ACOG Practice bulletin No. 201: Pregestational diabetes mellitus. Obstet Gynecol 132: e228-e248. [Crossref]

8. Rajab KE, Issa AA, Hasan ZA, Rajab E, Jaradat AA (2012) Incidence of gestationa diabetes mellitus in Bahrain from 2002 to 2010. Int J Gyncaeol Obstet 117: 74-77.

9. Canadian diabetes association clinical practice guidelines expert committee (2013) Clinical practice guidelines: diabetes and pregnancy. Can J Diabetes 37: S168-S183.

10. American Diabetes Association (2019) Classification and diagnosis of diabetes. Diabetes Care 42: S13-S28.

11. KHUH Hospital Policy on Management of Diabetes Mellitus and Gestational Diabetes.

Copyright: (C2021 AlKhalifa MA. This is an open-access article distributed under the terms of the Creative Commons Attribution License, which permits unrestricted use, distribution, and reproduction in any medium, provided the original author and source are credited. 